\title{
VHF Series-Input Parallel-Output Interleaved Self-Oscillating Resonant SEPIC Converter
}

Kovacevic, Milovan; Knott, Arnold; Andersen, Michael A. E.

Published in:

Proceedings of ECCE USA 2013

Link to article, DOI:

10.1109/ECCE.2013.6646959

Publication date:

2013

Link back to DTU Orbit

Citation (APA):

Kovacevic, M., Knott, A., \& Andersen, M. A. E. (2013). VHF Series-Input Parallel-Output Interleaved SelfOscillating Resonant SEPIC Converter. In Proceedings of ECCE USA 2013 (pp. 2052-2056). IEEE. https://doi.org/10.1109/ECCE.2013.6646959

\section{General rights}

Copyright and moral rights for the publications made accessible in the public portal are retained by the authors and/or other copyright owners and it is a condition of accessing publications that users recognise and abide by the legal requirements associated with these rights.

- Users may download and print one copy of any publication from the public portal for the purpose of private study or research.

- You may not further distribute the material or use it for any profit-making activity or commercial gain

- You may freely distribute the URL identifying the publication in the public portal 


\title{
VHF Series-Input Parallel-Output Interleaved Self-Oscillating Resonant SEPIC Converter
}

\author{
Milovan Kovacevic, Arnold Knott, Michael A. E. Andersen \\ Department of Electrical Engineering \\ Technical University of Denmark \\ Kgs. Lyngby, Denmark \\ Email: \{mikov, akn, ma\}@elektro.dtu.dk
}

\begin{abstract}
If the switches of two resonant SEPIC converters are capacitively coupled, it is possible to obtain a self-oscillating converter in which the two power stages operate in interleaved mode. This paper describes a topology where the inputs of two SEPIC converters are connected in series, thereby sharing the input voltage. For the same output power and switching frequency, the voltage stress of the switches is reduced by a factor of two while the voltage transformation ratio is doubled. This modification is possible with addition of only two capacitors in the power stage and a biasing circuit. Design considerations and challenges are investigated. To verify the proposed design, a $70 \mathrm{~V}$ input, $37 \mathrm{MHz}$ prototype was built using low-cost switching and passive components, and experimental results are presented. Peak observed efficiency was $82 \%$.
\end{abstract}

\section{INTRODUCTION}

Reducing the physical size of electronic equipment in power applications is desired in order to add more features into existing products, integrate power converters in places normally unfit for such equipment, and reduce system cost. Increasing the operating frequency of the converter is a direct way of reducing the size of energy storage elements such as bulky capacitors and inductors, which usually dominate the overall converter volume.

However, the challenges that arise when the converter operating frequency is increased into the Very High Frequency (VHF) band ranging from $30 \mathrm{MHz}$ to $300 \mathrm{MHz}$ are numerous. Conventional converter topologies become impractical due to high switching and gating losses [1]. Furthermore, it becomes increasingly difficult to implement high-side drivers, imposing additional limitations on converter topology selection. In recent publications, zero-voltage-switching (ZVS) converters with ground-referenced switches were almost exclusively used [2]-[8]; the only exceptions are low-voltage applications and converters-on-chip [9].

Switching losses in power semiconductor devices (discharge of the transistor parasitic output capacitance through the transistor on-resistance in a hard-switched design as well as current-voltage overlap during rise and fall times of the switching device) increase rapidly with frequency, thereby significantly reducing overall efficiency. Furthermore, parasitic reactive components cannot be ignored, since their sizes are comparable with the low capacitances and inductances resulting from the high frequency design. Commercial gate drivers for operation at $\mathrm{VHF}$ are rare; the fastest solution was introduced by IXYS for operation up to $45 \mathrm{MHz}$ [10]. However, this driver is relying on hard-switching of the MOSFET gate, introducing significant gating loss. Therefore, no efficient readily available gate driver IC solution exists. To obtain gate-driving signals, VHF converters today are either oscillator-driven [3], [11] or self-oscillating [12], [13].

With the exception of the $\Phi_{2}$ inverter [14] and the resonant boost converter from [5], ZVS topologies typically used today are derived from or related to class E amplifier. As a consequence, the switches are exposed to high voltage stress, typically 3.6 to 4 times the input voltage at $50 \%$ duty cycle [15]. This limits the selection of the switching devices to those with high voltage rating, which implies either higher parasitic capacitances or higher on-resistance compared to a lowvoltage components. In either case, worse performance and higher losses are expected. Converters based on $\Phi_{2}$ inverter require additional passive components in the resonant tank, which increases the converter size and complexity and increase the conduction losses. The resonant VHF boost converter is more space/component-efficient, and the voltage stress is the same as in the conventional boost, but it is only able to stepup the input voltage; therefore is not suitable for applications where step-down voltage conversion is required.

Recently, a method for achieving self-oscillating operation of two interleaved converters has been developed [7], [16], which addresses the gate signal generation with low component count, but the voltage stress was still 3 times the input voltage. This paper presents a modification of the interleaved self-oscillating resonant SEPIC converter [16] where the converter inputs are connected in series. Compared to the parallel-input parallel output converter, the voltage stress is reduced by a factor of two, while the voltage transformation ratio is increased by the same factor for the same output power and switching frequency. This allows a wider selection of switching devices for a given input voltage, since the breakdown voltage handling capability requirement is reduced. Furthermore, it is possible to obtain galvanic isolation between the input and the output of the converter. Only a few additional passive components in the circuit are required. Section II introduces the circuit topology and operation principle. Section III presents experimental results from a designed prototype. Section IV discusses the design considerations and challenges. Finally, section V concludes the paper. 


\section{Circuit Operation}

Fig. 1 shows the topology of the proposed converter. Two resonant SEPIC converters [2] are capacitively coupled together, so the drain voltage of one MOSFET is used to drive the gate of the other MOSFET. Therefore, the converters operate with a phase-shift of $180^{\circ}$ (interleaved operation). The oscillations are started automatically when the bias voltage is increased above threshold voltage (self-oscillating operation) [7], [16]. If the power stages are identical, the input voltage is shared equally between the inverter stages. The inverters are capacitively coupled to the rectifier stages via $C_{I F}-C_{I R}$ capacitor pairs. $C_{I R 1}$ and $C_{I R 2}$ are bulk capacitors, providing DC blocking and low AC impedance between the primary (input) grounds and secondary (output) ground. Therefore, the ground of the rectifiers is "floating" in respect to the ground voltage on the input side. Isolation strength is determined by the voltage rating of $C_{I F}-C_{I R}$ capacitor pairs.

As described in [16] for the parallel-input ISOR SEPIC (shown in Fig. 2), the switching frequency may be approximately determined as

$$
f_{S}=\frac{1}{2 \pi \sqrt{L_{I} C_{D S, t o t}}}
$$

where $C_{D S, \text { tot }}$ is the total drain capacitance seen by a switch when the rectifier is shorted:

$$
C_{D S, t o t}=C_{D S}+C_{G D}+C_{I}+\frac{C_{1}\left(C_{G S}+C_{2}\right)}{C_{1}+C_{G S}+C_{2}}
$$

In Fig. 3, typical waveforms of the proposed converter are presented. Gate voltages $v_{G S 1}$ and $v_{G S 2}$ are scaled versions of $v_{G S 2}$ and $v_{G S 1}$ voltage, respectively, by a factor defined by the capacitive voltage divider; DC values of $v_{G S 1}$ and $v_{G S 2}$

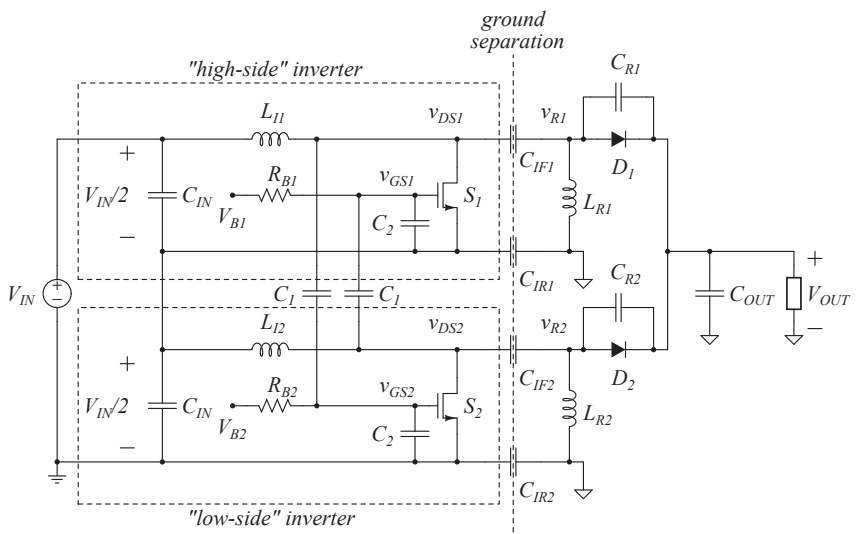

Fig. 1: Schematic of the interleaved self-oscillating resonant (ISOR) SEPIC converter with series input and parallel output (SIPO), and galvanic isolation between the inverter and the rectifier stages. "High-side" and "low-side" inverters share the input voltage. The stages are coupled via the same capacitive network as in a standard ISOR SEPIC converter.

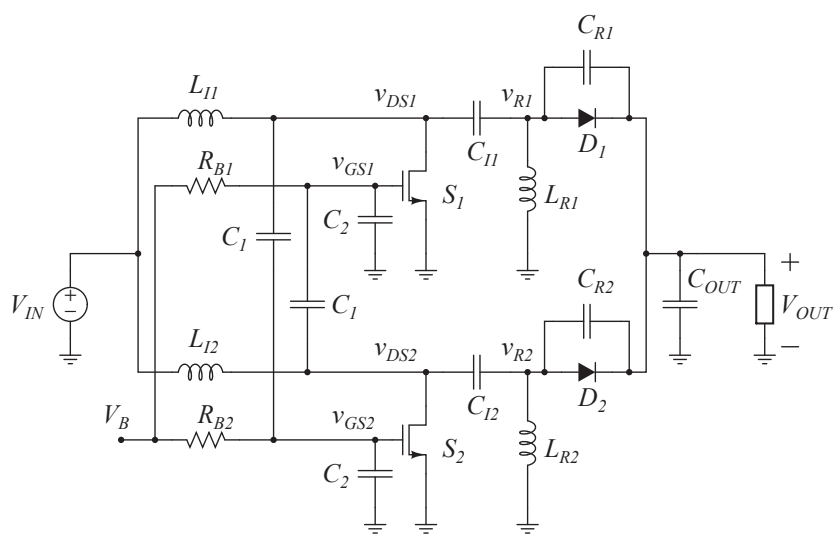

Fig. 2: Schematic of the (parallel-input parallel-output) ISOR SEPIC converter, which does not have galvanic isolation between the input and the output.
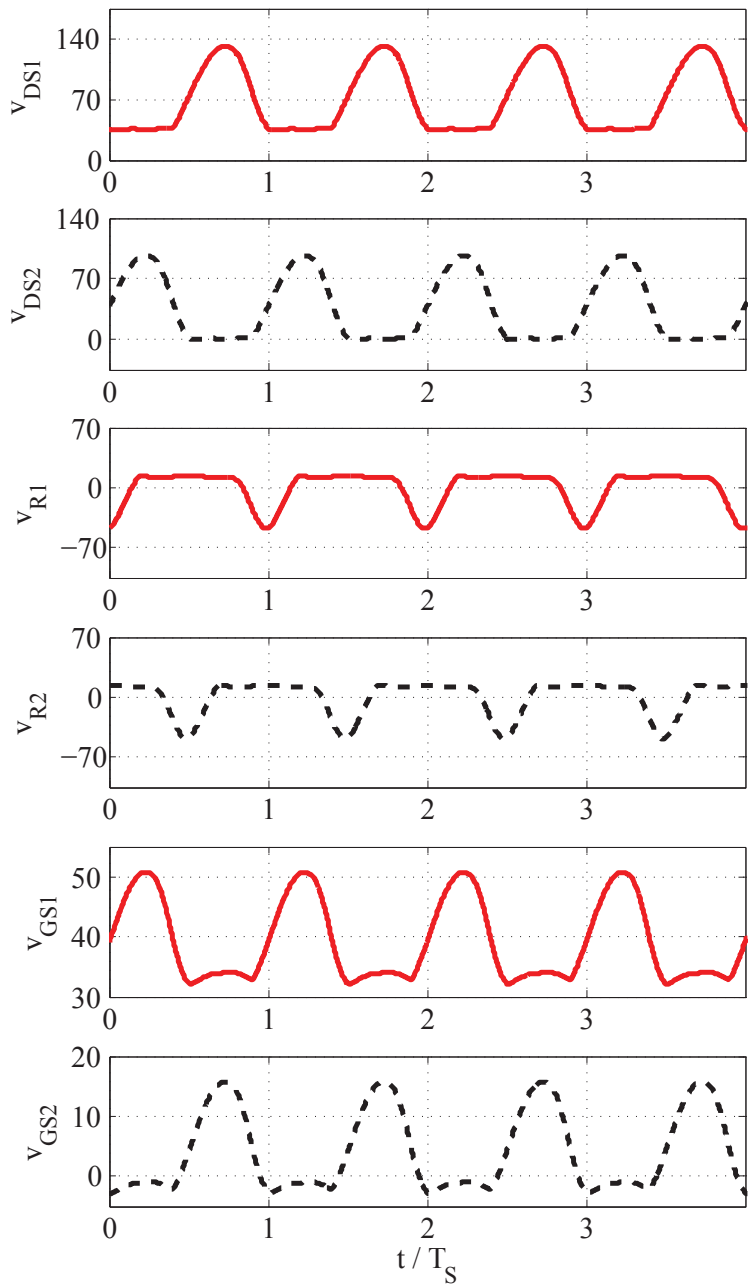

Fig. 3: Simulated waveforms of the drain, rectifier, and gate voltages of the SIPO ISOR SEPIC converter with respect to ground at the input. $V_{I N}=70 \mathrm{~V}$ and $V_{O U T}=12 \mathrm{~V}$. Time scale is normalized to the switching period $T_{S}$. 
set by $V_{B 1}$ and $V_{B 2}$, respectively:

$$
\begin{aligned}
v_{G S i}(t) & =V_{B i}+v_{D S j, a c}(t) \frac{C_{1}}{C_{1}+C_{2}+C_{G S}+C_{G D}} \\
i, j & =\{1,2\}
\end{aligned}
$$

Initial input voltage distribution between the converters may be set by a pair of balancing resistors or evening out the current consumption in the biasing circuits.

\section{EXPERIMENTAL RESULTS}

To verify the proposed design, a proof-of-concept prototype was experimentally evaluated. The converter operation parameters are shown in Table I. Components used in the prototype are standard, low-cost semiconductor devices and passives. Capacitors in the resonant tank are 5\% tolerance $\mathrm{COG}$ ceramics. A complete component list is provided in Table II. Values for parasitic capacitances of the MOSFET are taken from the datasheet: $C_{G S}=100 \mathrm{pF}, C_{D S}=21 \mathrm{pF}$, and $C_{G D}=7 \mathrm{pF}$. Due to nonlinear nature of $C_{D S}$ and $C_{G D}$ and their dependence on $v_{D S}$, representative values of these capacitances are taken at the average value of $v_{D S}$, which is $V_{I N}$. With the listed components, from (1) the switching frequency is calculated as

$$
\begin{aligned}
f_{S} & =\frac{1}{2 \pi \sqrt{150 \mathrm{nH}(22 \mathrm{pF}+7 \mathrm{pF}+66 \mathrm{pF}+21 \mathrm{pF})}} \\
& =38.15 \mathrm{MHz}
\end{aligned}
$$

The achieved converter switching frequency was $37.2 \mathrm{MHz}$, which is a $2.6 \%$ error from the value predicted by (1). Efficiency of $82 \%$ was obtained for a $12 \mathrm{~W}$ output power; the power loss is mainly contributed by the conduction loss in the input inductor and the switch due to low Q-factor at the operating frequency, and the high on-resistance of the MOSFET.

Measured waveforms of the important voltages in the converter are shown in Fig. 5. All measurements were obtained with the oscilloscope probe connected in series with a small capacitance; therefore, the presented waveforms are scaleddown versions of the real voltages, with removed DC value. The reason for doing so is to reduce the influence of the probe on the converter operation due to impedance imbalance between $d_{1}$ and $d_{2}$. A $2.2 \mathrm{pF}$ capacitance was used in for drain and rectifier voltages, and $10 \mathrm{pF}$ for the gate voltage measurements. This introduces scaling factors of 0.18 and 0.51 in the respective waveforms for a $9.5 \mathrm{pF}$ passive oscilloscope probe.

High-frequency ringing is observed on top of the shown voltage waveforms, caused by the parasitic inductances of the components and the layout; especially the rectifier and the gate voltages are affected. Simulations in Spice suggest that the ringing in the rectifier while the diode is $\mathrm{ON}$ is due to the diode parasitic inductance, which resonates with $C_{I}$ when the switch is $\mathrm{ON}$, and $C_{I}$ in series with equivalent drain-source capacitance $C_{D S}$. Similar effect holds for the stray inductance in the MOSFETs with $C_{I}$ and $C_{R}$. The the gate signal ringing is caused by a superposition of two effects: gate parasitic

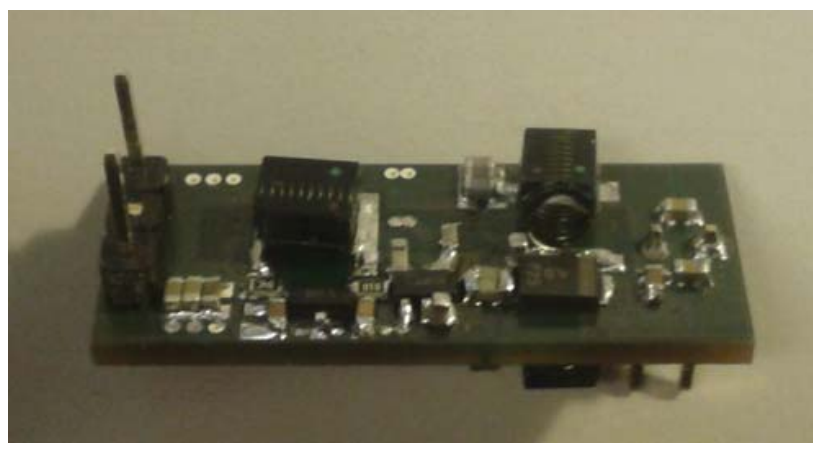

Fig. 4: Photograph of the experimental prototype.

TABLE I: Converter operation parameters.

\begin{tabular}{lr}
\hline input voltage $V_{I N}$ & $70 \mathrm{~V}$ \\
output voltage $V_{O U T}$ & $12 \mathrm{~V}$ \\
output power $P_{O U T}$ & $12 \mathrm{~W}$ \\
switching frequency $f_{S}$ & $37.20 \mathrm{MHz}$ \\
\hline
\end{tabular}

TABLE II: List of the converter components.

\begin{tabular}{lr}
\hline Component & Value \\
\hline \hline$L_{I 1}, L_{I 2}$ & Coilcraft $150 \mathrm{nH}$ \\
$L_{R 1}, L_{R 2}$ & Coilcraft $150 \mathrm{nH}$ \\
$C_{I 1}, C_{I 2}$ & $66 \mathrm{pF}(\mathrm{C} 0 \mathrm{G})$ \\
$C_{I R 1}, C_{I R 2}$ & $780 \mathrm{pF}(\mathrm{C} 0 \mathrm{G})$ \\
$C_{1}$ & $27 \mathrm{pF}(\mathrm{C} 0 \mathrm{G})$ \\
$C_{2}$ & - \\
$C_{I N}$ & $9.4 \mathrm{uF}(\mathrm{X} 7 \mathrm{R})$ \\
$C_{O U T}$ & $9.4 \mathrm{uF}(\mathrm{X} 7 \mathrm{R})$ \\
$S_{1}, S_{2}$ & $\mathrm{IR} \mathrm{IRF5802}$ \\
$D_{1}, D_{2}$ & NXP PMEG6010 \\
\hline
\end{tabular}

inductance ringing with the gate capacitance, and the insertion of the ringing from the power stage through $C_{1}$ and $C_{G D}$.

Due to imperfect matching between the components, the mid-point voltage between the converters was $33.5 \mathrm{~V}$ instead of intended $35 \mathrm{~V}$ when $V_{B 1}$ and $V_{B 2}$ are generated with biasing resistors. The reason is that the power stage with lower input voltage will have a lower bias voltage as a consequence, which further results in lower output power. Still, the converter shows a reasonably good self-balancing with no external intervention. When the biasing circuit is implemented with voltage references (VRs) in series with resistors, as shown in Fig. 6, the mid-point voltage increases to $35.5 \mathrm{~V}$, thereby reducing the input voltage difference below $1.5 \%$. The resistors in series to VRs are used to reduce the 


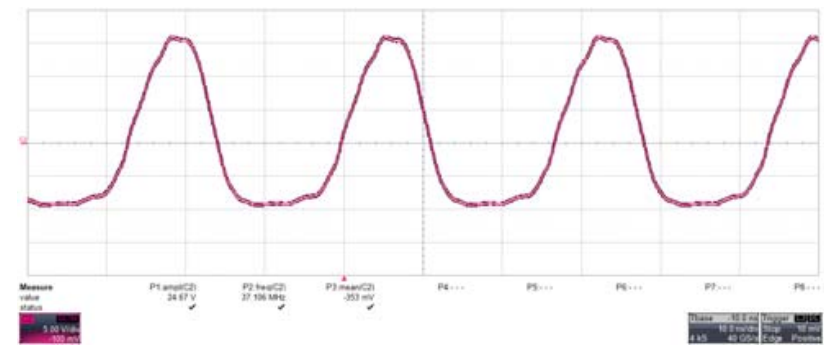

(a) $v_{D S 1}: 5 \mathrm{~V} / \mathrm{div}, 10 \mathrm{~ns} / \mathrm{div}$, scaling factor 0.18

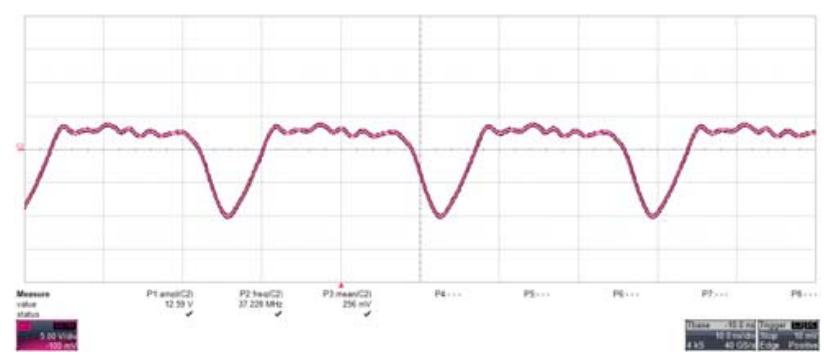

(b) $v_{R 1}: 5 \mathrm{~V} / \mathrm{div}, 10 \mathrm{~ns} / \mathrm{div}$, scaling factor 0.18

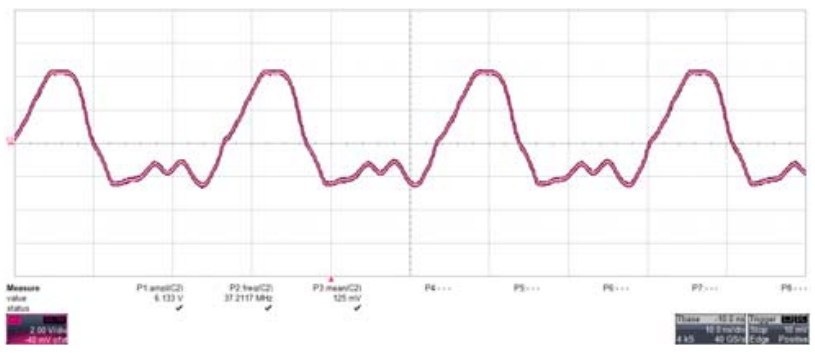

(c) $v_{G S 1}: 2 \mathrm{~V} / \mathrm{div}, 10 \mathrm{~ns} / \mathrm{div}$, scaling factor 0.51

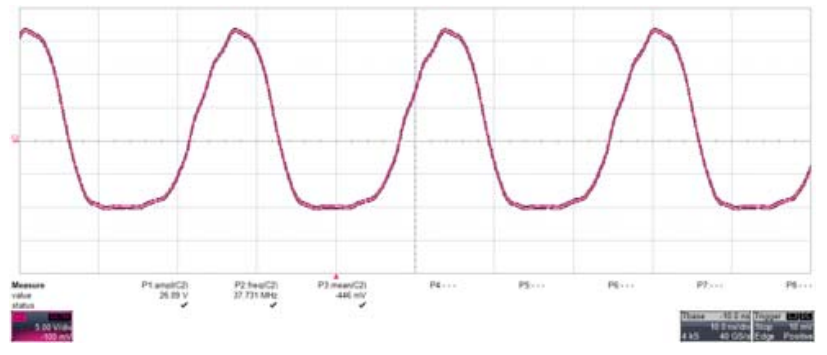

(d) $v_{D S 2}: 5 \mathrm{~V} / \mathrm{div}, 10 \mathrm{~ns} / \mathrm{div}$, scaling factor 0.18

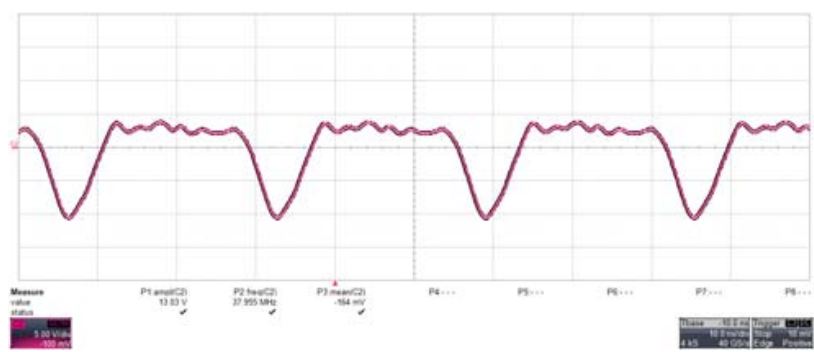

(e) $v_{R 2}: 5 \mathrm{~V} / \mathrm{div}, 10 \mathrm{~ns} / \mathrm{div}$, scaling factor 0.18

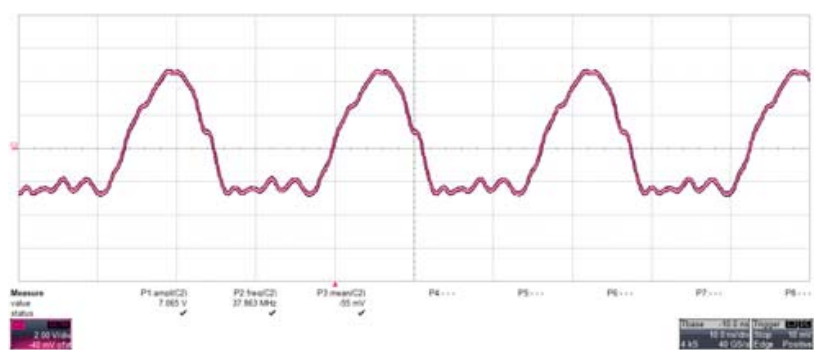

(f) $v_{G S 2}: 2 \mathrm{~V} / \mathrm{div}, 10 \mathrm{~ns} / \mathrm{div}$, scaling factor 0.51

Fig. 5: Experimental waveforms of the $35.3 \mathrm{MHz}, 70 \mathrm{~V}$ input converter. The measurements were performed with small capacitances in series with the measurement probe to reduce the influence of the probe capacitance on the circuit operation.

power consumption of the references and to postpone the turnon of the converter until the input voltage reaches $70 \mathrm{~V}$.

\section{DISCUSSION}

If the converters are ideally matched, the input voltage is shared equally between the converters. In practical implementation, the matching is never ideal and imbalance will appear in a certain degree. There are three main contributors to the imbalance in the proposed converter: asymmetry in the circuit layout, component variations, and difference in the gate bias voltages.

In order to suppress the imbalance, the converter layout has to be carefully designed. In the implementation described in this work, the layout is axially symmetrical (see Fig. 7), dictated by the pin placement of the switches. The components need to be chosen with tight tolerances. To improve capacitance matching, two or three capacitors may be used instead of one in order to reduce the equivalent series inductance and average the deviation from the desired value. This is particularly important for the gate-driving interconnection network as it influences amplitude of $v_{G S 1}$ and $v_{G S 2}$. Use of C0G/NP0 capacitors is recommended in order to suppress the voltage and
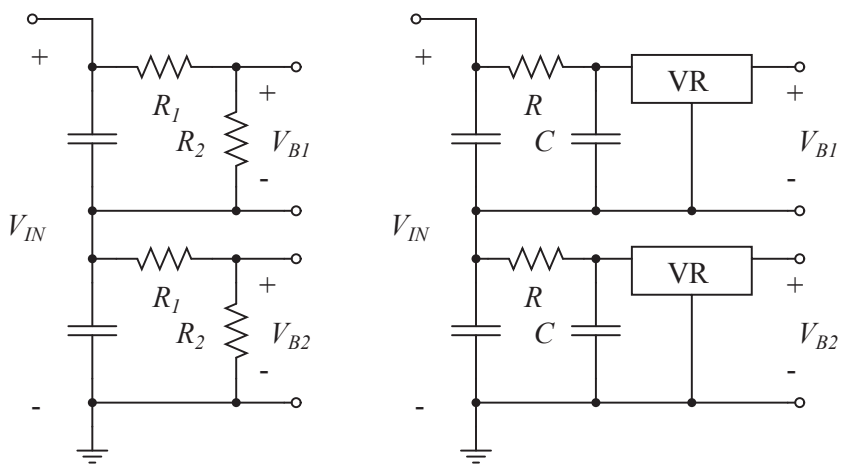

Fig. 6: Biasing circuits: passive with resistors (left) and with voltage references (right).

temperature dependence on the circuit capacitances, as well as for their high-frequency performance [17]. To further reduce variations in the converter components, as well as to increase power density of the converter, inductors may be implemented in the PCB [18].

The output power does not vary significantly with the gate 


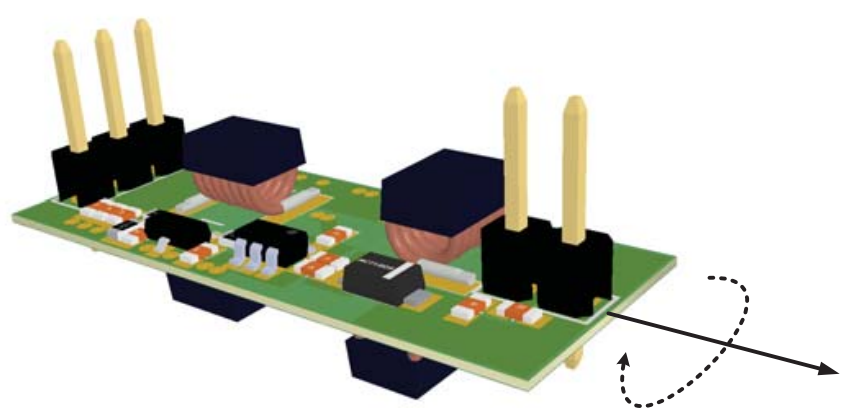

Fig. 7: Axial symmetry of the layout and component placement on the PCB.

bias voltage. However, a difference will appear if $V_{B 1} \neq V_{B 2}$. The most simple way to obtain $V_{B 1}$ and $V_{B 2}$ is by two pairs of biasing resistors. However, it does not guarantee equal input voltage sharing between the converters. Therefore, 5 $\mathrm{V}$ linear regulators are used to provide the bias voltages for the MOSFET gates, which has reduced the voltage imbalance between the converter inputs below $1.5 \%$.

VHF converters are typically regulated using burst-mode [2]-[4] and bias voltage modulation control [5]. The interleaved converter does not show significant variation at the output with modulation of the bias voltage, therefore the converter output regulation may be obtained by implementing the burst-mode control scheme for wide load range. A mechanism for turning the "high-side" and "low-side" MOSFETs on and off needs to be provided. It is however significantly easier compared to topologies which utilize true high-side switches. The implementation of the control scheme is a subject of ongoing research.

Stacking of the inverter stages in series is not limited to 2. Each inverter may be used to drive additional inverters. The practical limitation is that the equivalent drain-source capacitance increases with each inverter stage. As a result, $C_{I F}$ needs to be increased to maintain ZVS operation [16]. Moreover, from (1) it may be concluded that $f_{S}$ will also be reduced. To maintain $f_{S}$, input inductance needs to be reduced in value, which as a consequence results in more power per converter stage. The complexity of the control circuitry also increases, as more outputs are required in the gate driver.

\section{CONCLUSION AND FUTURE WORK}

In this paper, the series-input parallel-output configuration of the interleaved self-oscillating resonant SEPIC topology was introduced. This topology allows a reduction of the switch voltage stress and increases the voltage transformation ratio by a factor of two compared to the parallel-input paralleloutput ISOR SEPIC converter. This is achieved using a very small number of standard, low-cost components. Upsides and downsides of the presented converter are discussed, and guidelines for circumventing them are proposed. Due to non-ideal matching between the converters, additional effort is required to obtain ideal voltage balance between the converters. Proposed solution resulted in less than $1.5 \%$ in voltage difference between the input stages. Measured waveforms of a $70 \mathrm{~V}$ input, $35 \mathrm{MHz}$ converter were provided, reaching efficiency of $82 \%$. As a part of the ongoing research, output regulation scheme is to be implemented. Inductors may be printed on the PCB to further increase power density and performance repeatability of the circuit.

\section{REFERENCES}

[1] J. M. Rivas, D. Jackson, O. Leitermann, A. D. Sagneri, Y. Han, and D. J. Perreault, "Design consideration for very high frequency dc-dc converters," in IEEE Power Electronics Specialists Conference (PESC), Jeju, South Korea, Jun. 2006, pp. 1-11.

[2] J. Hu, A. D. Sagneri, J. M. Rivas, Y. Han, S. M. Davis, and D. J. Perreault, "High frequency resonant sepic converter with wide input and output voltage ranges," IEEE Trans. Power Electron., vol. 27, no. 1, pp. 189-200, Jan. 2012.

[3] J. M. Rivas, O. Leitermann, Y. Han, and D. J. Perreault, "A very high frequency dc-dc converter based on a class $\phi_{2}$ resonant inverter," IEEE Trans. Power Electron., vol. 26, no. 10, pp. 2980-2992, Oct. 2011.

[4] R. C. N. Pilawa-Podgurski, A. D. Sagneri, J. M. Rivas, D. I. Anderson, and D. J. Perreault, "Very-high-frequency resonant boost converters," IEEE Trans. Power Electron., vol. 24, no. 6, pp. 1654-1665, Jun. 2009

[5] P. Shamsi and B. Fahimi, "Design and development of vhf resonant dcdc boost converters," IEEE Trans. Power Electron., vol. 27, no. 8, Jun. 2012.

[6] M. P. Madsen, A. Knott, and M. A. E. Andersen, "Very high frequency resonant dc/dc converters for led lighting," in Proc. The Applied Power Electronics Conference and Exposition (APEC), Long Beach, California, USA, Mar. 2013, pp. 835-839.

[7] M. Kovacevic, A. Knott, and M. A. E. Andersen, "Interleaved selfoscillating class e derived resonant dc/dc converters," in Proc. International Conference on Electrical and Computer Systems (ICECS), Ottawa, Canada, Aug. 2012, pp. (192-)1-8.

[8] M. P. Madsen, A. Knott, and M. A. E. Andersen, "Proc. low power very high frequency converter with high step down ratio," in AFRICON2013, pending, Mauritius, Sep. 2013.

[9] M. Alimadadi, S. Sheikhaei, G. Lemieux, S. Mirabbasi, W. G. Dunford, and P. R. Palmer, "A fully integrated $660 \mathrm{mhz}$ low-swing energyrecycling dc-dc converter," IEEE Trans. Power Electron., vol. 24, no. 6, pp. 1475-1485, Jun. 2009.

[10] I. Corporation, "Dual 15 a low-side ultrafast mosfet driver." [Online]. Available: http://ixapps.ixys.com/DataSheet/ixdd415.pdf

[11] J. S. Glaser and J. M. Rivas, "A $500 \mathrm{w}$ push-pull dc-dc power converter with a $30 \mathrm{mhz}$ switching frequency," in IEEE Applied Power Electronics Conference and Exposition (APEC), Palm Springs, California, USA, Feb. 2010, pp. 654-661.

[12] H. Hase, H. Sekiya, J. Lu, and T. Yahagi, "Design and experimental results of resonant dc/dc converter with class e oscillator," in Interna tional Workshop on Nonlinear Circuit and Signal Processing (NCSP'05), Hawaii, USA, Mar. 2005, pp. 219-222.

[13] T. Andersen, S. Christensen, A. Knott, and M. A. E. Andersen, "A vhf class e dc-dc converter with self-oscillating gate driver," in Proc. Applied Power Electronics Conference and Exposition (APEC), San Francisco, California, USA, Sep. 2011, pp. 885-891.

[14] J. M. Rivas, Y. Han, O. Leitermann, A. D. Sagneri, and D. J. Perreault, "A high-frequency resonant inverter topology with low-voltage stress," IEEE Trans. Power Electron., vol. 23, no. 4, pp. 1759-1771, Jul. 2008

[15] N. O. Sokal and A. D. Sokal, "Class e - a new class of high-efficiency tuned single-ended switching power amplifiers," IEEE J. Solid-State Circuits, vol. 10, no. 3, pp. 168-176, Jun. 1975.

[16] M. Kovacevic, A. Knott, and M. A. E. Andersen, "A very high frequency interleaved self-oscillating resonant sepic converter," in Proc. European Conference on Power Electronics and Applications (EPE), pending, Lille, France, 2013.

[17] Murata Manufacturing Co., Ltd., www.murata.com

[18] M. P. Madsen, A. Knott, and M. A. E. Andersen, "Printed circuit board embedded inductors for very high frequency switch-mode power supplies," in Proc. International Energy Conversion Congress and Exhibition (ECCE Asia), Melbourne, Australia, Jun. 2013, pp. 10711078. 